\title{
Conservation Plans - A Model for Economic Exploitation
}

\author{
I. Schnell* and B. Barzilay
}

Geography and Human Environment Department, Tel Aviv University, Ramat Aviv 69978, Israel

\begin{abstract}
Building conservation is a cultural phenomenon in the urban landscape, occurring by means of turning culture into a tradable product. In the article we illustrate that building conservation, serves the wealthy by means of the symbolic value given to these buildings and their surroundings, while those who pay the price are the poor. The conservation plan of Tel Aviv is examined against the failures detailed in the Planning and Construction Law. We argue that the approval process that the conservation plan follows results in planning that ignores the negative external impact on the immediate environment, and directs the economic benefits to the upper classes, at the expense of the owners of the bordering land, who in many cases belong to the lower classes. These pay the price for the planning, due to the legal failures detailed, but are not entitled to reimbursement for the planning damages. This article exposes the legal mechanisms that channel the profits from the conservation plan to the upper classes.
\end{abstract}

\section{INTRODUCTION}

Directing capital to a group of wealthy people by governmental, legislative means while devolving the external, negative impact on the masses that do not enjoy the positive effect is not a new or unfamiliar phenomenon. One of the researchers dealing with this issue. Harvey, D. (2001) [1] did not examine the degree of connection between the ruling authority and interest groups, and argued that this should be studied $[1,2]$. Harvey does not present the mechanisms by which the wealthy exploit the state of affairs for their benefit, other than one statement regarding the constitutional tool used to direct the profits. He does not give details, nor does he illustrate this mechanism, and how it works in directing the situation to the benefit of the wealthy. De Shalit, A. (2004) [3] agrees with this position, but also does not indicate the legal mechanisms that make it possible.

In the course of this article, we will try to reveal one of the legal mechanisms enabling the wealthy to exploit the space for their benefit, which is the Planning and Construction Law, and in particular article 197 (compensation in respect of planning damages). Article 197 of the Planning and Construction Law in Israel allows those who have been damaged by the planning processes to make a claim against the local committee in respect of the damage caused to them. The damage is measured in terms of the reduction in the financial value of the property, and compensation is given in money, equal in value to the damage and intended to restore the injured party to his financial situation prior to the damage. We will claim that although this article creates the impression among readers that it upholds an egalitarian and balanced distribution of the public burden, the true content of the article, known only to the professionals, in practice prevents the real injured parties from being compensated for planning damages and results in a particular group of the public bearing the costs of conservation, while the financial

*Address correspondence to this author at the Geography and Human Environment Department, Tel Aviv University, Ramat Aviv 69978, Israel;

E-mail: schnell@post.tau.ac.il profits goes to line the pockets of the wealthy. It will also be argued that this failure was known and familiar to the planning authorities even before approval of the conservation plan, and therefore there is a suspicion that the decision makers are in league with the capitalists in order to enable this result.

\section{THE STRUCTURE OF THE ARGUMENT}

Our main argument is that conservation plans, in Israel in general and in Tel-Aviv-Jaffa in particular, have created business opportunities through the acquisition of buildings slated for conservation by increasing the value of deteriorating property [4], when the existing owners of the rights cannot meet the financial burden of the cost of conservation. These original owners have been forced to sell their properties at a reduced price, and thus have absorbed the cost of conservation while making way for interest groups to promote real estate interests.

Among the systems of laws that bridge the public need for ownership rights is the provision of section 197 (a) of the planning and building law:

\begin{abstract}
"If land located within the bounds of the plan or bordering thereon is by a plan, not by way of appropriation, the party who, on the date of commencement of the plan, was the owner of the land or the holder of rights therein is entitled to damages form the local committee, subject to the foregoing in section $200 "$ ".
\end{abstract}

Israel's Article 197 is ostensibly intended to protect these injured parties and afford them compensation for the decreased value of their properties, in the amount of the cost of conservation that is imposed on them. Here we see one of the mechanisms of failure that has been introduced into the law (article 197), limiting the possibilities for injured parties to protect themselves by preventing them from claiming the compensation granted under this article, in complete contradiction to the declared objective of the article. Not only does this legal mechanism prevent the equal distribution of the public burden, but these loopholes make it easier for the 
planning authorities to approve plans of this kind. In this discussion we will relate, as said, to the conservation plan of the city of Tel Aviv.

The research is based on three main value appraisals of samples of houses, which were assigned for conservation. The first two projects were submitted to the municipality and their results are first analyzed in these articles. They studied the physical conditions of the houses (2003) and the values of conservation and market value before and after conservation $^{1}$ of 28 selected buildings in central Tel-Aviv. We repeated their study on a sample of 40 more buildings in TelAviv. The results are calculated from these studies.

\section{THE CONSERVATION PLAN}

The conservation plan is perceived as a "cultural space", which is a combination of a "place" or landscape bearing values, and their cultural significance for a society with particular characteristics $[5,6]$. At the same time, apart from the cultural significance of the place, it also has economic significance, and it functions according to "market rules". The structure and the culture are resources that satisfy spiritual needs [7], and are not merely products or services. "This is consumption of symbolic significance", operating according to the rules of the market - supply and demand, profit and benefit, and for this reason there is no difference between consumption of symbolic significance and the consumption of a product or services [5]. The original reasons for conserving cultural assets are not economic, but the economy provides the factor that enables conservation of the asset.

The value of a conserved property derives, among other things, from its rarity [8]. Apart from rarity, a building listed for conservation also projects a message of stability, continuity and trust, and thus the old building has a marketing value on its own part, which is also translated into economic value [9]. The economic value of the old building is exploited mainly by luxury restaurants, insurance companies, financial services, and public relations agencies, and from their standpoint, the image of stability and continuity take on a marketing aspect. This is directly connected with leisure culture, the service economy, and the increased standard of living [10]. The commercialization of culture and its aspects in the urban landscape is prominent in tourist attractions and in the utilization of historic structures for purposes of leisure, entertainment and recreation [8]. It has been found that important centers of global tourism spread along rivers, lakes and seashores where there is a concentration of heritage sites. In terms of the tourist experience, this produces a combination of shopping, entertainment, and soaking up history, all "on the same ticket" [10].

Conservation can also result from political motivation. Heritage sites are used to promote the power and interests of a particular group in the present time [11]. An examination of the motives for conserving buildings shows that decisions with regard to the values, the myths, and ways of presenting them through cultural heritage buildings vary from period to period, and from one social group to another; they disappear, enjoy renewed appreciation, change, and are adapted to the

${ }^{1}$ Rot-Levy, S. (2003) Unpublished report submitted to the Municipality of Tel-Aviv-Jaffa that compares the values of restricted and unrestricted buildings for conservation. characteristics and needs of present-day society. Culture is given economic significance since a cultural environment creates a good business atmosphere.

In the modern era of the consumer society, a new cultureconsuming middle class has sprung up. This class is based on a non-productive employment structure (financial consultants, lawyers, advertising agents, public relations consultants etc.), which nonetheless serves as the backbone of the economy [12]. Agents from each of these social categories, want to reinforce its lifestyle and differentiate itself from other groups. One of the means available to a group to differentiate itself from other groups is the acquisition of luxuries (symbolic capital), for example, designer labels, labels of culinary refinement (wines, cheeses, gourmet restaurants, etc.), and architecture $[13,14]$. The rise of symbolic significance in everyday life has contributed to the creation of symbolic capital, manifested, in the case under examination, in listed buildings.

The modernist era was characterized by a trend of population migration from the old metropolitan centers to the periphery. This migration led well-off population groups to move to the suburbs, resulting in the physical and social deterioration of the old metropolitan center. By contrast, recent decades have seen the reverse trend of moving from the outer metropolitan rings to the old centers of the metropolis. This new immigration to the city center put under pressure the land values of properties in the city center [15].

\section{THE EMERGENT NEED FOR A SECOND CONSER- VATION LEGISLATION}

In 1984, when it was decided to establish the Council for the Preservation of Buildings and Historic Sites in Israel, emphasis was given to the fear that hundreds of sites representing the last authentic remains of historic settlement and the architectural processes characterizing the development of culture in Israel over the past 300 years would disappear [16]. The founders of the Council had in mind the sites of Jewish settlements in pre-state Israel, those relating to Zionist settlement, from the end of the 19th century and up to the establishment of the state in 1948. The Council's aim was to wake up the public and influence public attitudes towards historic sites in Israel [16]. In 2002 when the heads of the Council looked for international recognition from UNESCO's worldwide organization for the preservation of cultural assets (ICOMOS) and entry into the World Cultural Heritage List, they needed to emphasize the universal importance of the site intended for conservation. On the implementation side, in order to cope with the demand for residential and business uses on the one hand, and preservation of the local heritage on the other hand, the authority of Tel-Aviv needed to produce planning and legal solutions originating in urban building plans [17].

In this essay, we have chosen to focus on the conservation plans for Tel Aviv. The main reason is the experience accumulated to date in broad conservation areas and different conservation styles, making it possible to examine the difference between one style and another.

In a framework of two conservation plans for the city of Tel Aviv alone, plan 2650a and 2650b (p.p 4987 21.5.2001), over two thousand buildings were listed for conservation in 2001 only. In the plans, there is a distinction between build- 
ings where there are no stringent building restrictions, and buildings where there are stringent restrictions and no additional construction is permitted, other than internal alterations. In addition, preservation areas have been decided on, which include buildings listed for conservation alongside others that are not. As a result, conservation plans covers not only two thousand listed buildings, but also tens of thousands of buildings within the preservation area.

Tel Aviv's conservation instructions cause broad economic implications, including: 1. a prohibition against replacing decorative tiles with modern tiles, or erasing murals; 2. apertures - a prohibition against replacing original doors, windows and shutters with new ones that do not match the original, installing wooden windows that are not identical to the original, replacing clear glass with milk glass, or alternatively, original colored glass with clear glass; 3 . a prohibition against replacing the existing mosaic tiles with another facing material such as ceramic, stone, etc.; 4. a prohibition against changing the original mailboxes; 5. a prohibition against removing or changing wall facings; technical installations, air conditioning, auxiliary structures - installing airconditioners on the facade or forward sides of the building is prohibited. Air-conditioners may be installed on the underside of rear facing balcony roofs, with a concealing panel and painted grille. Technical installations such as sun heaters may not be placed on the roof if they protrude above the structural parapet, etc.

In practice, carrying out small-scale actions such as installing an air-conditioner, replacing tiles inside the building, and so on, requires actions that according to our estimations can cost between US\$15,000 and $\$ 25,000$ for conservation alone, excluding the cost of the renovation itself. It must be remembered that the existing tenants of conservation buildings in Tel Aviv belong to a low class population group.

The above requirements carry a financial cost that is sometimes far in excess to the requirements of the work that the tenant wants to carry out. This is where developers have found business opportunities in purchasing the buildings. As stated, this is where article 197 of the Planning and Construction Law should come into force, to protect the injured parties and give them compensation for the reduced value of their assets, due to the extra conservation costs to which they are subject. In reality, it has been found that this section contains lacunae making it possible to route the planning to places where the injured public is prevented from receiving compensation.

\section{THE MECHANISM OF THE LEGAL FAILURE}

Although the planning and building law, by means of section 197 thereof, allows for the payment of compensation for damage caused by planning activity, it has been found that this section contains lacunae making it possible to route the planning to places where the injured public is prevented from receiving compensation.

The "reasonable violation" test makes it possible to harm the individual for the common good, provided the violation is "reasonable".

The "obsolescence" test reduces the period of obsolescence for lawsuits in respect of external hazards to three years.
Failure of the provision of limitation of the plan. The main contributor to the reduction of value due to declaring the building listed for conservation results from fear of high costs of adaptation and renovation. It is not possible to assess in advance the full costs of adapting the building until the work is carried out. "Clause 197 (b) of the article stipulates that "suitcase will be delivered to the local comity within 3 years (from permission of conservation plans)". "This clause is liable to create a situation in which the greater part of the right to make a claim expires before the work is carried out."

Failure of the provision regarding reasonable damage. Section 200 of The Planning and Construction Law, as interpretated by supreme court (c.c. 86/483, Birenbach V. local committee of Tel Aviv, v. mb(3) 228) permits causing damage to an individual for a general benefit, subject to a number of legal restrictions. One of the restrictions that is relevant to the case is that the damage is reasonable. The reasonableness of the damage is examined according to the degree of reduction in value (the percentage of damage relative to the original value of the building). With regard to buildings listed for conservation, we are postulating that there is potential for failure of the market to anticipate the costs of conservation. It is not possible to prove that the damage goes beyond the bounds of what is reasonable until the conservation is carried out in practice, but by then the limitation of time laid down in the law comes into force.

In view of these failures as detailed above, an anomaly is created in that the plan exempts itself from the application of article 197 of the Planning and Construction Law (compensation in respect of damages caused by the plan). The original owner of the building is required to take on a very heavy financial burden, which, in the majority of cases, the financial benefits involved in conserving the building does not cover.

Under these circumstances the law prevents a building owner from making any renovations that are necessary for performing decent standard of living like adding an air conditioning to the apartment. Every simple action, requires initial costs of tens of thousands of dollars, which cannot be covered by planning damages. In this situation, owners of property are liable to find themselves in situations where they are forced to sell the properties, whose values have fallen, at a lower price than neighboring properties that have not been declared for conservation This is where the developers step in, benefiting from buying the property cheaply. The wealthy developers are in a position to initiate a program of changes, to bargain with the authorities in order to achieve maximum profit, through building additions, removing conservation restrictions, and so on.

\section{MALFUNCTIONS IN THE AUTHORITY'S SYSTEM OF CONSIDERATIONS}

Following up the process of approval of the Tel Aviv conservation plan produces more than a reasonable suspicion that the decision-makers were aware of the failure of the law, and decided to ignore it.

At a discussion of the objections to the plan (Subcommittee B for Objections, at meeting no. 862 of December 19, 2004) it was noted, after preliminary examination, that in most of the buildings for conservation, the incentive appear- 
ing as compensation in the plan is limited, and is not sufficient to cover the cost of the conservation renovation in practice. Accordingly, the committee decided to increase the incentive, but the increased incentive was not brought up for public examination and criticism (since it was in the framework of a decision regarding an objection). Furthermore, the committee proposed that anyone claiming compensation in respect of a reduction in value due to approval of the plan would lose the benefits afforded by the plan. Only after the intervention of the person investigating the objections on behalf of the committee, who recommended not making the incentive conditional on the absence of a claim, did the committee decides to accept his recommendation.

The committee was aware of the failure with regard to the limitation of claims for compensation in respect of planning damages following approval of the conservation plan. In article 11 of the resolution passed by this same meeting, it states: "In accordance with the recommendations of the investigator, the committee appeals to the Minister of the Interior to give his approval, in this special case of a first plan of its kind for building conservation, to extend the date for submitting claims under article 197 beyond the three years laid down in the law. The committee authorizes the chair of the district committee to appeal to the Minister of the Interior on its behalf in this matter" (Subcommittee B for Objections, at meeting no. 862 of December 19, 2004). The recommendation, incidentally, was not carried out.

From the minutes of the discussion on the objections to the decision to approve the plan in the district committee, we learn that the local planning and construction committee had in mind the anticipated claims for compensation ${ }^{2}$. This played a part in their considerations. Moreover, in the same decision we can see the conscious attempt by the local committee to introduce the compensation claim into the mechanism of legal and economic failure. Thus, for example, the proposal by the local community to reduce benefits (mobility of rights, additional building rights) for those suing the local committee for damages caused by the plan, until this decision was removed at the recommendation of the objections investigator.

\section{THOSE INJURED BY THE PLANS}

The conservation actions imposed upon the owners of the buildings have economic implications for property values, and broader implications for the capital market in general. An example of the effect of conservation on the capital market can be seen in Rothschild Boulevard, which is in part a conservation area, being turned into a major financial center of the city of Tel Aviv [18].

This forced action is liable to produce a decrease in property values, due to the reduction in options for realizing the assets. Whereas before the imposition of the restrictions owner of the rights to a property could demolish or preserve the building, depending on which would produce a higher financial return in the circumstances, the imposition of the new restrictions does not allow them the option of examining the most profitable alternative, and limits them solely to the

\footnotetext{
${ }^{2}$ Local planning committees are formal institutions that are subject to regional and the national committees of the Ministry of Interior.
}

conservation track, even if this does not represent the optimal economic choice.

As a result of the above, the imposition of conservation restrictions leads to a reduction in the value of apartments slated for conservation. That is, the cost of conservation is perceived by the market as being higher than the contribution of the historic value that lies in conservation to the value of the conserved property. The possible economic damage resulting from declaring a property to be a listed building has a number of main aspects.

First, Prolongation of the processes of planning and receiving permits for a property of this type, by comparison with a property without such restrictions. Second, the requirements to preserve a building whose construction conflicts with the instructions of the planning and construction regulations. (Here there is also likely to be a gap between the market value of a building that complies with the legislation and the market value of a building that does not comply with the legislation. Third, Even before the start of the conservation process, the owner of the property is required to spend considerable amount of money on the documentation of the building. This cost varies between $\$ 10,000$ and $\$ 20,000$, depending on the conservation requirements and their stringency. The special planning costs can also reach tens of thousands of dollars, because of the pace of work of the craftsmen on a project of this kind, the heavy responsibility that lies with the planner, the requirement of close supervision, and the difficulties of implementation. Fourth, The reduction in possibilities for utilizing surplus (unutilized) building rights. Fifth, The lack of certainty with regard to the state of the building (until the conservation work is carried out, it is hard to assess for certain the scale of construction work and the adaptations that will be needed).

The reduction in value is not fixed, but changes according to a whole set of factors. Among them are the conservation track, the nature of the building and quality of its construction, parking requirements and supplementary conditions for the building permit. In addition the reduction of value depends on the benefits from the conserved building such as the volume of construction obtained after conservation and the permitted uses after the conservation track.

The conservation restrictions are likely to affect basic functional possibilities and the user's basic benefit from use of the property. For example, when the owners of a listed property wanting to add an air-conditioning system finds themselves forced to carry out preliminary actions at considerable cost, they will be forced to forego basic benefits from the property. These restrictions are liable to force them to "give up" the building and find himself an alternative place that will allow them an acceptable quality of life with the financial means at these disposal. The sale of a property with conservation restrictions lowers its value, and in any event the owner of he apartments bears the financial cost We find that the owners of the apartment on whom conservation restrictions are imposed bears the main burden of the conservation costs alone, whether they sell the property or not, in view of all the failures detailed above, which result in the inability to apply article 197 of the Planning and Construction Law. 
A report requested by the Tel Aviv local planning and construction committee to look into the extra cost of renovating a conservation building as compared with a nonconservation building gave figures in the region of $\$ 150$ per sq $\mathrm{m}$ of International (Bauhaus) style construction, and $\$ 175$ per sq $\mathrm{m}$ for a building in the Eclectic style, with an average area of $1,000 \mathrm{sq} \mathrm{m}$ built as 6 units on three floors. This is an estimated cost, and cannot be assessed more accurately until the renovation itself. For a four-room apartment with an average area of $100-110 \mathrm{sq} \mathrm{m}$, the cost will be in the region of $\$ 15,000$ - $\$ 20,000$. These costs are liable to apply even to people wanting to carry out simple actions such as installing air-conditioning.

The price of conservation represents a possible (although not necessarily intentional) tool for encroaching on a poor population group, one that is exploited by developers. One manifestation of this can be seen in the petition by objectors to the conservation plan, according to which homeowners living in buildings slated for conservation are held hostage for years. They cannot renovate their homes because of the high cost of renovation and the convoluted bureaucracy. On the other hand, they cannot sell them because they are crumbling (Toister, Globes February 27, 2005, Real Estate column). Even if these homes are sold, their value will be reduced by the cost of conservation that will be imposed on the buyer, and in any event the full cost is levied from the property owners.

In terms of the ethnic-geographic spread of the conservation plans, these plans have been drawn up in areas occupied from the start by populations that are characteristically of medium to low socio-economic status. The Neve Zedek neighborhood, Kerem Hateimanim, conservation neighborhoods in Jaffa are examples of areas where the veteran residents have difficulty benefiting from the conservation. These are neighborhoods where the buildings have been subject to ongoing neglect. The conservation plans lower the prices of apartments, and thus provide an incentive for forcing out those who cannot meet the financial costs even of making simple and routine improvements. This provides business opportunities for developers who buy properties at a low cost embodying the fact that they are listed for conservation.

A comparative appraisal of residential apartment deals was carried out by Shmuel Penn ${ }^{3}$ in the Lev Ha'Ir and White City areas, comparing buildings not listed for conservation with buildings in the same area that are listed for conservation (before conservation has been carried out). In Lev Ha' Ir, no difference was found in the price per room between listed and unlisted buildings. On the other hand, in the White City the value of a listed building was $6 \%-7 \%$ lower than the value of an unlisted building (Original survey). In addition, an appraisal was carried out by Shlomo Rot-levy (2003) comparing fourteen buildings for conservation with stringent restrictions, and another sixteen listed buildings without stringent restrictions, deducting the cost of conservation as estimated by an engineering firm dealing with building conservation, at the request of Tel Aviv Municipality This survey found that there is a negative effect of close to 10 per-

\footnotetext{
${ }^{3}$ Penn, S. (2003) Unpublished report submitted to the Municipality of TelAviv-Jaffa on the physical conditions of building for conservation. TelAviv-Jaffa.
}

cent on the value of the listed buildings. Conservation properties for which there are stringent restrictions are affected more than those for which the conservation does not involve stringent restrictions.

\section{THE BENEFICIARIES OF THE PLANS}

The Tel Aviv conservation plan places greater emphasis on the preserved building, and less on the public space that surrounds it. In this way, the cost of conservation is limited to the owners of the land on which the listed buildings stand, and the general public is not affected. In places where the owner of the apartment is the true bearer of the conservation costs and does not belong to the group of those entitled to reimbursement for the damages of the plan, developers that are close to the decision makers in the municipality find ways to convince the municipality to allow changes in the original plans in order to increase profitability pf the conservation.

The conservation image has a positive financial value for an area that benefits from this message [4]. At the same time, the value of a property listed for conservation is reduced relative to that of a property not listed for conservation. As a result, while the circle of those benefiting from the conservation message is broad, and spreads beyond the listed buildings themselves, those who bear the burden of conservation are the owners of the listed properties. So far there are no evidences that they sold their property at higher prices than their neighbors who did not bear the price of the conservation as the report of the investigator of objections to the Tel Aviv conservation plan testifies: "No unequivocal researchbased proof has been found to indicate an increase in the value of buildings after conservation by comparison with the same buildings that have undergone regular but meticulous renovation" (Toister, Globes February 27, 2005, Real Estate column).

Since the value of the listed property is reduced, as stated, when it is listed, it follows that the financial cost of conservation imposed on the owner of the property, as perceived in the real estate market, is higher than contribution to the value of the property of the historic value embodied in the conservation. It has been found that buildings in the conservation area benefit from the message and image of the conservation value, even though they do not bear the conservation costs. This environment is another beneficiary of the conservation plans that does not bear the cost of conservation, alongside the developers who benefit from the economic potential of the listed property itself.

\section{CONCLUSIONS}

The neo-Marxist tradition recognizes the directing of economic benefits from urban ventures to the capitalists while the costs - in the form of the negative, external impact - are imposed on a public that does not benefit from the venture $[1,2,13]$. However, the main criticism argues that this tradition does not deal with the mechanisms that enable this phenomenon.

The external effects that are made possible by the enterprise arise mainly from world views and policies, or economic interests of large-scale capitalists and those who do their bidding among the decision-makers. Some of the mechanisms used by the group of capitalists to direct bene- 
fits towards themselves are governmental, legislative devices.

In a media age, when the importance of environmental issues is on the public agenda, the decision-makers cannot ignore the public voice and they take steps to legislate laws with an environmental orientation. Ostensibly, these environmental laws are intended for the general public and work to their benefit. Although public opinion pushes legislators to take decisions with an environmental orientation, the constitutional tool serves the capitalist group as a mechanism for directing the benefits towards themselves, while imposing any negative environmental effects on the public, which does not benefit from these ventures. This idea appears to be in complete contradiction to the environmental concept proposed by the laws themselves. The question of how this contradiction is possible, how this constitutional mechanism works is the focus of this essay.

While the legislators and the capitalists are forced to cope with sharp public criticism that does not allow them to ignore environmental considerations, this essay distinguishes between the overt mechanism - the environmental mechanism operating for the benefit of the public and reflected in the system of laws - and the covert mechanism that serves the capitalists. The overt mechanism is the environmental laws with which we are familiar, and which operate for the benefit of the general public and their environment. The overt mechanism in this essay is the conservation plan, which is based on a real need and is the subject of broad consensus among the public. By contrast with the overt mechanism, with its ostensible environmental orientation, there is a covert mechanism. This mechanism appears to be found in the form of a conservation plan that is compatible with the inbuilt failures in the legislation, in the advance knowledge that they are in the range of the legal failure. This mechanism enables the cost of the conservation plan to be imposed on a public that cannot be compensated for the planning damages caused to it, while on the other hand transfers the economic profit embodied in the conservation plans directly to the pocket of the capitalists, who have not participated in the real costs of the plan.

The covert mechanism proposed in this essay enables the economic benefits from ventures to be directed to the wealthy, at the expense of the public that pays the price. Accordingly, the covert mechanism represents a model that complements the general model emphasizing study of the mechanism.
We have chosen to call this a "concealed mechanism", since the general public has a favorable impression of the law that it sees, and what is written in it. The public does not see what is not written in the law. Sometimes what does not appear in the law emasculates that which does appear openly. In these cases, the law (the overt mechanism) represents lip service on the part of the public's elected representatives, while the real content of the law is to be found in what is not written in it.

\section{REFERENCES}

[1] Harvey D. Spaces of capital towards a critical geography. Edinburgh: University Press 1994; p. 2001.

[2] Harvey D. Justice, nature, and geography of difference. Oxford: Basil Blackwell 1996.

[3] De Shalit A. Red - green democracy, Justice and quality of the environment. Babel Press (Israeli Environment), Hashal Center (The Israeli Institute for Environmental Thought and Leadership) 2004.

[4] Barzilay B. Conservation of buildings - economic culture or cultural economics? Land 2004; c(2): 12-26.

[5] Amit-Cohen I. The 'White city': Preservation and functional changes in the old center of Tel Aviv. In: Maos M, Inbar M, Shmueli DF, Eds. Contem Israeli Geogr, Haifa: Dep. Of Geography University of Haifa 2004; pp. 51-60.

[6] Jameson P. Postmodernism or the cultural logic of enlightened capitalism, Reflect Press 2002.

[7] Urry J. The tourist gaze. $2^{\text {nd }}$ ed. London: Sage Publications 2001; pp. 2-3.

[8] Ashworth GJ. From history to heritage: From heritage to identity: In search of concepts and models. In: Ashworth GJ, Larkham PJ, Eds. Building a new heritage, tourism, culture and identity in the New Europe, London and New York, Routledge 1994; pp. 13-30.

[9] Levin MV. Downtown redevelopment as an urban growth strategy: A critical appraisal of the Baltimore renaissance. J Urban Aff 1987; 9: 103-23.

[10] Bramwell B. User satisfaction and product development in urban tourism. Tour Manag 1998; 19(1): 35-46.

[11] Osborne BS. Constructing landscapes of power: The george etienne cartier monument, montreal. J Hist Geogr 1998; 24(4): 431-58.

[12] Knox PL. The restless urban landscape, economic and sociocultural change and transformation of metropolitan Washington DC. Ann Am Assoc Geogr 1991; 81(2): 181-209.

[13] Harvey D. The condition of postmodernity. Oxford: Basil Blackwell 1989.

[14] Harvey D. The urban experience. Oxford UK \& Cambridge USA: Blackwell 1989.

[15] Hall P. Cities of tomorrow: An intellectual history of urban planning and design in the twentieth century. Oxford: Basil Blackwell 1988.

[16] Barzilay B, Schnel I. Conservation plan. Land 2008; G(2): 10-21.

[17] Ruling OM 1991/95 (Tel Aviv District Court, before the honorable Judge G. Kling) The Tenants of 9 Gordon St. Tel Aviv v. the Tel Aviv Local Planning and Construction Committee et al. Tak-Mach 96; (3): 3543.

[18] Nitzan-Shiftan A. Whitened houses. In theory and criticism. Theory Decis 2000; 16: 229-231. 